\title{
Effect of Electroless Pretreatment on the Distribution of Etched Tunnels on Aluminum Foil
}

\author{
Haobin Wei ${ }^{1}$, Huining Huang ${ }^{1}$, Ning Peng ${ }^{1,2,{ }^{*}}$, Hehua Yao ${ }^{1}$ \\ ${ }^{1}$ Guangxi Key Laboratory of Electrochemical and Magnetochemical Functional Materials, Guilin \\ University of Technology, Guilin, 541004, China \\ ${ }^{2}$ Institute of Technology Research and Development of Electronic Aluminum Foil, Guangxi Hezhou \\ Guidong Electronics Technology Co. Ltd., 542800 Guangxi, China \\ *E-mail: $\underline{\text { ncdxclpn@glut.edu.cn }}$
}

doi: $10.20964 / 2020.09 .66$

Received: 3 May 2020 / Accepted: 30 June 2020 / Published: 10 August 2020

The merged tunnels intensely reduced the specific surface area of etched aluminum foil using in aluminum electrolyte capacitor, which restrict the increase of the specific capacitance. In this paper, the nano-scale Sn nuclei was fabricated on aluminum surface by electroless plating to improve the surface area. The uniformly distributed Sn nuclei on aluminum surface could serve as the pitting initiation sites, due to the composition of Al-Sn localized micro-batteries. The distribution of the etched tunnels for the aluminum foil with proper $\mathrm{Sn}$ nuclei are improved significantly in contrast with that for the conventional aluminum foil, resulting in the enhancement of the specific surface area.

Keywords: Aluminum; SEM; Polarization; Pitting Corrosion;

\section{$\underline{\text { FULL TEXT }}$}

(C) 2020 The Authors. Published by ESG (www.electrochemsci.org). This article is an open access article distributed under the terms and conditions of the Creative Commons Attribution license (http://creativecommons.org/licenses/by/4.0/). 